\title{
GLASS FIBER-REINFORCED POLYESTER COMPOSITE FATIGUE CRACK MONITORING USING ACOUSTIC EMISSION
}

Samira Gholizadeh ${ }^{1}$, Z Leman ${ }^{1}$, Btht Baharudin ${ }^{2}$, and O Innayatullah ${ }^{1}$

${ }^{1}$ Affiliation not available

${ }^{2}$ School of Engineering and Technology (Mechanical Engineering), University Collage of Technology Sarawak (UCTS)

February 16, 2022

\section{Hosted file}

GLASS FIBER-REINFORCED POLYESTER COMPOSITE FATIGUE CRACK -ICSTEM.pdf available at https: //authorea.com/users/441662/articles/553383-glass-fiber-reinforced-polyester-compositefatigue-crack-monitoring-using-acoustic-emission 